\title{
Oncogene Associated cDNA Microarray Analysis Shows PRAME Gene Expression is a Marker for Response to Anthracycline Containing Chemotherapy in Patients with Diffuse Large B-cell Lymphoma
}

\author{
Riko Kawano, ${ }^{1,3)}$ Kennosuke Karube, ${ }^{3)}$ Masahiro Kikuchi, ${ }^{2)}$ Morishige Takeshita, ${ }^{2)}$ Kazuo Tamura, ${ }^{1)}$ \\ Naokuni Uike, ${ }^{4)}$ Tetsuya Eto, ${ }^{5)}$ Koichi Ohshima, ${ }^{3)}$ and Junji Suzumiya ${ }^{1,6}$
}

CHOP (cyclophosphamide, adriamycin, vincristine, and prednisolone) therapy achieves a response in more than $60 \%$ patients with diffuse large B-cell lymphomas (DLBCLs). However, DLBCL shows a heterogeneous response to chemotherapy, and some patients are refractory to CHOP therapy. This difference in response to therapy is most likely due to differences in biological characteristics. We used cDNA microarray analysis to identify genes differentially expressed in anthracycline containing chemotherapy-resistant DLBCLs (7 patients) compared with anthracycline containing chemotherapy-sensitive DLBCLs (6 patients). Nine genes on the cDNA chip showed increased expression in anthracycline containing chemotherapyresistant patients. We chose the preferentially expressed antigen of melanoma (PRAME) gene because it showed the highest expression in anthracycline containing chemotherapy-resistant DLBCLs on the cDNA chip, and it has been linked to prognosis of hematological malignancies. We also examined the relationship between PRAME gene expression and progression-free survival (PFS) in 45 patients with DLBCL. The progression-free survival of PRAME-positive patients $(\mathrm{n}=12)$ was significantly worse than that of PRAME-negative patients $(\mathrm{n}=33)(p=0.0373)$. Our results therefore indicate that PRAME expression in DLBCL correlates with response to anthracycline containing chemotherapy. 〔J Clin Exp Hematopathol 49(1): 1-7, 2009]

Keywords: diffuse large B-cell lymphoma, anthracycline containing chemotherapy resistant, preferentially expressed antigen of melanoma (PRAME) gene

\section{INTRODUCTION}

Diffuse large B-cell lymphoma (DLBCL) is the most common type, accounting for $30 \%$ to $40 \%$ of non-Hodgkin lymphoma. However, DLBCL is clinically and morphologically heterogeneous, despite the use of chemotherapy (CHOP : cyclophosphamide, adriamycin, vincristine, and prednisolone). ${ }^{1}$ In addition, CHOP-treated patients sometimes become resistant to therapy. ${ }^{2}$ It is therefore important

\footnotetext{
Received : January 15, 2008

Revised : October 28, 2008

Accepted: December 3, 2008

${ }^{1)}$ First Department of Internal Medicine and ${ }^{2)}$ Department of Pathology, School of Medicine, Fukuoka University, and ${ }^{33}$ Department of Pathology, School of Medicine, Kurume University, ${ }^{4}$ Department of Hematology National Kyushu Cancer Center, ") Department of Hematology Hamanomachi Hospital, ${ }^{6}$ Second Department of Internal Medicine, Fukuoka University Chikushi Hospital, Fukuoka, Japan

Address correspondence and reprint request to Koichi Ohshima, M.D., Department of Pathology, School of Medicine, Kurume University, Asahimachi 67, Kurume, Fukuoka 830- 0011, Japan.

E-mail : ohshima_kouichi@med.kurume-u.ac.jp
}

to identify at diagnosis those patients who may benefit from more aggressive or experimental therapies.

Some proteins have been implicated in tolerance to cancer treatment, such as multidrug-resistance-related protein 1 (MRP1), and lung-resistance protein (LRP). ${ }^{3}$ While no data have been reported yet regarding mediators of CHOP tolerance, such information would definitely be useful for choice of treatment. Currently, the prognosis of patients with DLBCL is estimated on the basis of clinical parameters specified by the International Prognostic Index (IPI). However, these clinical parameters reflect a mixture of underlying biological and genetic differences. To elucidate these underlying factors, the prognostic value of numerous individual proteins has been studied with immunoperoxidase and molecular techniques. ${ }^{4-6}$ These studies have yielded conflicting results, none of which have been validated in a large prospective trial. In contrast to the IPI parameters, these individual markers are therefore generally not used in clinical practice for selecting therapy or establishing prognosis.

Gene expression analysis using cDNA microarrays has 
Table 1. Clinical features of patients examined by microarray analysis

\begin{tabular}{|c|c|c|c|c|c|c|c|c|c|}
\hline No. & $\begin{array}{l}\text { Age/ } \\
\text { Sex }\end{array}$ & Stage & Extranodal site & LDH & $\begin{array}{c}\text { Performance } \\
\text { status }\end{array}$ & Therapy & Effect & $\begin{array}{l}\text { Overall } \\
\text { survival } \\
\text { (months) }\end{array}$ & Status \\
\hline \multicolumn{10}{|c|}{ Anthracycline containing chemotherapy-resistant patients } \\
\hline 1 & $79 / \mathrm{F}$ & $4 \mathrm{~A}$ & stomach & $>\mathrm{N}$ & 0 & VEPA & PD & 9 & Death \\
\hline 2 & $57 / \mathrm{F}$ & $2 \mathrm{~A}$ & & $>\mathrm{N}$ & 0 & VEPA & $\mathrm{PD}$ & 9 & Death \\
\hline 3 & $58 / \mathrm{M}$ & $2 \mathrm{AEX}$ & stomach & $\mathrm{N}>$ & 1 & CHOP & PD & 7 & Alive \\
\hline 4 & $69 / \mathrm{F}$ & $3 \mathrm{As}$ & & $>\mathrm{N}$ & 1 & THP-COP & PD & 13 & Death \\
\hline 5 & $66 / \mathrm{M}$ & 4B & bone marrow & $>\mathrm{N}$ & 1 & $\mathrm{CHOP}$ & PD & 6 & Death \\
\hline 6 & $58 / \mathrm{M}$ & 3Bs & spleen & $>\mathrm{N}$ & 2 & THP-COP & PD & 5 & Death \\
\hline 7 & $61 / \mathrm{M}$ & $3 \mathrm{BE}$ & stomach & $>\mathrm{N}$ & 2 & THP-COP & PD & 2 & Alive \\
\hline \multicolumn{10}{|c|}{ Anthracycline containing chemotherapy-sensitive patients } \\
\hline 8 & $51 / \mathrm{M}$ & $4 \mathrm{~A}$ & bone, pleura, spleen & $>\mathrm{N}$ & 0 & CHOP & $\mathrm{CR}$ & 156 & Alive \\
\hline 9 & $76 / \mathrm{F}$ & $2 \mathrm{~A}$ & & $\mathrm{~N}>$ & 0 & CHOP & $\mathrm{CR}$ & 24 & Alive \\
\hline 10 & $67 / \mathrm{F}$ & $2 \mathrm{~A}$ & & $\mathrm{~N}>$ & 0 & CHOP & $\mathrm{CR}$ & 36 & Alive \\
\hline 11 & $67 / F$ & $3 \mathrm{Bs}$ & spleen & $>\mathrm{N}$ & 0 & VEPA & $\mathrm{CR}$ & 48 & Alive \\
\hline 12 & $72 / \mathrm{M}$ & $2 \mathrm{~A}$ & & $\mathrm{~N}>$ & 0 & VEPA & $\mathrm{CR}$ & 36 & Alive \\
\hline 13 & $67 / \mathrm{M}$ & 3As & spleen & $>\mathrm{N}$ & 2 & THP-COP & $\mathrm{CRu}$ & 14 & Alive \\
\hline
\end{tabular}

LDH : lactate dehydrogenase, N : normal, VEPA ; vinblastine, etoposide, prednisone, doxorubicin, CHOP ; cyclophosphamide, adriamycin, vincristine, prednisolone, THP-COP ; tetrahydropyranyl adriamycin, cyclophosphamide, vincristine, prednisolone, CR ; complete remission, $\mathrm{PD}$; progressive disease, $\mathrm{CRu}$; complete remission uncertain, $\mathrm{M}$; male, $\mathrm{F}$; female

been used to divide DLBCL into three prognostically significant subgroups based on expression profiles : germinal center B-cell like (GCB), activated B-cell like (ABC), or type 3.,8 The GCB group has a significantly better survival rate than the $\mathrm{ABC}$ group. The type 3 group is heterogeneous and not well defined, but shows a poor outcome similar to that of the ABC group. Another study using an oligonucleotide array classified DLBCL into two molecularly distinct populations (cured and fatal/refractory). ${ }^{9}$ Because the technology used to establish these classifications is expensive and not generally available, a simpler and more widely applicable method using immunohistochemistry to classify DLBCL into molecularly distinct and prognostically significant groups would be of enormous value in routine clinical practice. In addition, a method for predicting tolerance to first-time CHOP therapy is needed.

In this study, we used a microarray of human cDNAs comprising 884 transcribed elements to analyze gene expression profiles in DLBCL, with a view to developing a novel system for predicting responsiveness of an individual DLBCL patient to anthracycline containing chemotherapy. In this initial study, we identified a group of genes that were differentially expressed in 13 patients classified as anthracycline containing chemotherapy-resistant and seven who were responsive to the therapy.

In addition, we analyzed the relationship between these gene expressions and prognosis for 45 patients with DLBCL.

\section{MATERIALS AND METHODS}

\section{Patients}

We obtained informed consent from Japanese adult patients with DLBCL to obtain lymph node tissue samples prior to the administration of anthracycline containing chemotherapy (Table 1).

Diagnosis of DLBCL was established according to the WHO classification system.

\section{RNA isolation}

We confirmed that the tissue section samples contained neoplastic cells, were free of massive necrosis, and showed minimal contamination of fibrous tissue, adipose tissue or inflammatory cells. Total RNA was extracted and isolated from whole tissue sections with the guanidinium thiocyanatephenol-chloroform method using the Total RNA Separator kit (Clontech, Palo Alto, CA). The quality of RNA was analyzed by electrophoresis using the Agilent 2100 analyzer (Agilent Technologies, Palo Alto, CA) and cases were evaluated as to their suitability for microarray analysis.

\section{Microarray procedure}

mRNA was extracted from 13 patient samples (Table 1) for gene expression analysis using a cDNA-microarray sys- 
tem containing 884 oncogene cDNAs (Takara Bio, Otsu, Japan).

Five $\mu \mathrm{g}$ of total RNA from each sample was directly labeled with cyanine 3-conjugated dUTP (Cy3), and the same amount of Universal Human Reference RNA (Stratagene, La Jolla, CA) was labeled with cyanine 5-conjugated dUTP (Cy5) for reference. Cancer Chip ver. 4.0 (Takara Bio ; 884 genes) was used for all of the microarray studies. Hybridizations were performed as described previously. ${ }^{10)}$ After washing, the slides were scanned with a Scan Array 4000 scanner (GSI Lumonics, Boston, MA) and images were analyzed with the QuantArray (GSI Lumonics).

\section{Data analysis and clustering}

Data obtained from the hybridizations were stored in a database for analysis. The Cy3:Cy5 ratios were normalized to the median ratio value for all spots on the array. After normalization, spots with intensities in both channels of less than twice the local background were discarded. To statistically confirm the DLBCL-specific genes, the Student's t-test was used to compare anthracycline containing chemotherapyresistant and anthracycline containing chemotherapysensitive DLBCLs. Hierarchical clustering was applied to both axes by using the weighted pair-group method with centroid averaging as implemented in J-Express (http://www. molmine.com/indexj.html, http://www.uib.no/bjarted/iexpress/,Dr.MolMine,contact@molmine.com) and as described previously. ${ }^{10}$ To confirm the reproducibility of our microarray, we re-analyzed two patients. Hierarchical clustering showed that the data formed the same clusters, thus confirming the reproducibility of this analysis. Genes that showed marked differential expression in anthracycline containing chemotherapy-sensitive and anthracycline containing chemotherapy-resistant patients as determined with the Student's t-test $(p<0.05)$ were extracted and those with a more than three-fold difference between the two groups were selected.

The permutation test was added for multiple comparisons to obtain a more precise statistical comparison among these genes.

\section{Reverse transcriptase-polymerase chain reaction (RT- PCR)}

RT-PCR was performed on 45 DLBCL samples. c-DNA $(1 \mu \mathrm{g})$ generated from the isolated RNA was used for RTPCR analysis. A commercial PCR-kit (Amersham Biosciences, Uppsala, Sweden) was used with the following primers : OPC189 and OPC190 for preferentially expressed antigen of melanoma (PRAME) amplification (5'CTGTACTCATTTCCAGAGCCAGA-3'; OPC190, 5'TATTGAGAGGGTTTCCAAGGGGTT-3'). The PCR con- ditions for the PRAME gene were $5 \mathrm{~min}$ at $94^{\circ} \mathrm{C}$, followed by 45 cycles of $1 \mathrm{~min}$ at $94^{\circ} \mathrm{C}, 1 \mathrm{~min}$ at $55^{\circ} \mathrm{C}$, and $1 \mathrm{~min}$ at $72^{\circ} \mathrm{C}$. Four $\mu \mathrm{L}$ of each RT-PCR sample was run on a $2 \%$ agarose gel and visualized by ethidium bromide staining for determination of two categories, positive (band detected) and negative (band not detected).

\section{Statistical analysis}

Survival curves were calculated with the Kaplan-Meier method, and differences in survival rates were tested for significance by using the generalized logrank test. Differences were considered significant if the $p$ value was $<0.05$.

\section{RESULTS}

Seven anthracycline containing chemotherapy-resistant DLBCL patients and six anthracycline containing chemotherapy-sensitive DLBCL cases were analyzed by cDNA microarray technology. We analyzed the genes that were differentially expressed in the two patient groups (anthracycline containing chemotherapy-resistant and anthracycline containing chemotherapy-sensitive), and found distinct and reproducible differences in their expression patterns (Fig. 1).

Among 884 oncogene-encoding suppressors, mediators of proliferation and adhesion, cytokines, chemokines, and their receptors, we identified seven genes with a more than threefold difference in expression between anthracycline containing chemotherapy-resistant and anthracycline containing chemotherapy-sensitive patients (Table 2).

The PRAME gene showed increased expression in anthracycline containing chemotherapy-resistant patients, and CD79a showed reduced expression. In addition, we chose PRAME for further RT-PCR analysis of 45 DLBCLs because it showed the highest expression in anthracycline containing chemotherapy-resistant patients.

To examine survival rates, another group of 45 patients with DLBCL was analyzed (Table 3). The age of these patients ranged from 16 to 85 years (median, 64 years), and comprised 24 males and 21 females. All patients underwent anthracycline containing chemotherapy, and eight of 12 (66.6\%) PRAME-positive cases showed high-risk IPIs and 20 of 33 (60.6\%) PRAME-negative patients exhibited high-risk IPIs (Table 3).

Of the 45 patients showing progression-free survival (PFS), the PRAME-positive patients $(\mathrm{n}=12)$ had a significantly worse clinical outcome than the PRAME-negative patients $(\mathrm{n}=33)(P=0.0373$, Fig. 2$)$. Of the progressive disease (PD) patients, $50 \%$ were PRAME-positive, but only $18 \%$ of the complete remission (CR) patients were PRAMEpositive (Table 4). 


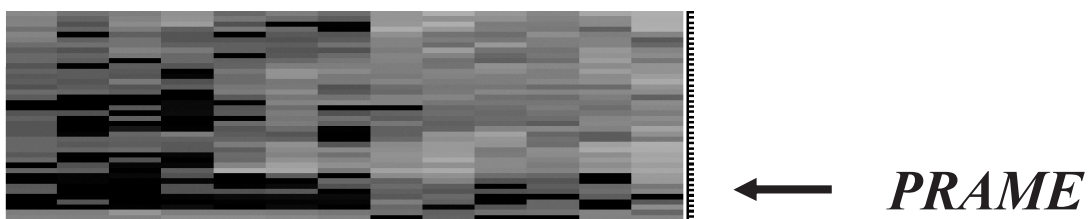

\section{Black: increased expression}

Gray: reduced expression

\begin{tabular}{|c|c|}
\hline $\begin{array}{l}\text { Anthracycline } \\
\text { containing } \\
\text { chemotherapy } \\
\text {-resistant patients }\end{array}$ & $\begin{array}{l}\text { Anthracycline } \\
\text { containing } \\
\text { chemotherapy }\end{array}$ \\
\hline
\end{tabular}

Fig. 1. Expression profiles of anthracycline containing chemotherapy-resistant and anthracycline containing chemotherapy-sensitive patients. The selected genes showed different expression patterns for anthracycline containing chemotherapy-resistant and anthracycline-sensitive patients.

Table 2. Gene expressions

\begin{tabular}{lc}
\hline \multicolumn{1}{c}{ Gene } & $\begin{array}{c}\text { Fold expression (control : non- } \\
\text { specific lymphadenitis) }\end{array}$ \\
\hline \multicolumn{2}{c}{ Increased expression } \\
\hline $\begin{array}{l}\text { preferentially expressed antigen in melanoma } \\
\text { trophoblast glycoprotein }\end{array}$ & 4.02 \\
cadherin 2, type 1, N-cadherin (neuronal) & 3.66 \\
BCL2/adenovirus E1B 19 kD-interacting protein 3 & 3.47 \\
keratin 19 & 3.36 \\
v-yes-1 Yamaguchi sarcoma viral oncogene homolog 1 & 3.21 \\
delta-like homolog (Drosophila) & 3.21 \\
multifunctional polypeptide similar to SAICAR synthetase & 3.18 \\
and AIR carboxylase & \\
\hline & \\
\hline IKK-related kinase epsilon ; inducible I $\varkappa$ B kinase & 0.32 \\
glutaredoxin (thioltransferase) & 0.28 \\
TAKARA_clone_ID27244 (CD79a) & 0.13 \\
major histocompatibility complex, class II, DP 08. 10. 28a1 & 0.08 \\
\hline
\end{tabular}

Among 884 analyzed genes encoding oncogenes, suppressors, proliferation mediators, adhesion proteins, cytokines, chemokines, and receptors, we found 7 genes were identified with a greater more than threefold difference between anthracycline containing chemotherapy-resistant and sensitive patients.

\section{DISCUSSION}

DLBCL comprises approximately $40 \%$ of all B cell lymphomas and survival can be predicted based on clinical parameters, as recently established by the International NonHodgkin's Lymphoma Prognostic Factors Project. To identify genes that are associated with progression of malig- nant lymphoma, the expression profiles of 18,432 genes were analyzed in DLBCLs at early (stages I and II, six cases) and advanced stages (stages III and IV, nine patients) by means of cDNA microarrays. ${ }^{11}$ However, no reliable measurable biological marker with prognostic value for patients with DLBCL has been identified. For the study reported here, we employed an effective method using cDNA microarray for 
Table 3. Clinical features of known progression-free survival patients $(n=45)$

\begin{tabular}{lcc}
\multicolumn{1}{c}{ Clinical features } & $\begin{array}{c}\text { PRAME-positive patients } \\
(\mathrm{n}=12)\end{array}$ & $\begin{array}{c}P R A M E \text {-negative patients } \\
(\mathrm{n}=33)\end{array}$ \\
\hline Sex & $\mathrm{M}: \mathrm{F}=8: 4$ & $\mathrm{M}: \mathrm{F}=16: 17$ \\
Median age in years (range) & $66(16-81)$ & $63(28-85)$ \\
Stage & 1 & 9 \\
1 & 3 & 10 \\
2 & 6 & 6 \\
3 & 3 & 20 \\
4 & 4 & 13 \\
IPI & 8 & 6 \\
low, low-intermediate & & 27 \\
high-intermediate, high & 6 & \\
Chemotherapy effect & 6 & \\
PD patients & 4 & \\
CR patients & &
\end{tabular}

IPI : International Prognostic Index, CR : complete remission, $\mathrm{PD}$ : progressive disease, $\mathrm{M}$; male, $\mathrm{F}$; female

The 45 DLBCL patients with PFS comprised 24 males and 21 females. Median age was 64 years. Eight of 12 (66.6\%) PRAME-positive patients presented with high-risk IPIs and $20(60.6 \%)$

$P R A M E$-negative patients exhibited high-risk IPIs.

predicting the success of anthracycline containing chemotherapy in DLBCL patients. With this method, patient samples were screened for gene expression. In the cDNA chips used in our study, the PRAME gene showed markedly increased expression in anthracycline containing chemotherapyresistant patients, and PT-PCR demonstrated that PRAMEpositive patients had a shorter PFS time than PRAMEnegative patients.

Gene expression analysis using cDNA microarrays has been used to divide DLBCL into prognostically significant subgroups based on expression profiles : germinal center Bcell-like (GCB), activated B-cell-like (ABC), or type 3.,8 GCB DLBCL expresses genes characteristic of germinal centre $B$ cells, while ABC DLBCL expresses genes normally induced during in vitro activation of peripheral blood $\mathrm{B}$ cells. Patients with GCB DLBCL had a significantly better overall survival rate than those with ABC DLBCL. A recent study analyzed the expression of 6,817 genes in tumor specimens from DLBCL patients who had undergone CHOP-based chemotherapy, and used a supervised learning prediction method to identify cured versus fatal or refractory disease. ${ }^{9}$ For example, the protein kinase $C-\beta 2$ gene was expressed at low levels in cured patients.

In our study, PRAME, trophoblast, and cadherin were shown to be increased expression, and CD79a was shown to be reduced expression in anthracycline containing chemotherapy-resistant patients. Trophoblast glycoprotein (5T4 oncofetal trophoblast glycoprotein, 5T4 antigen) expression is reported to be strongly associated with metastasis, ${ }^{12}$ and cadherin 2 (N-cadherin) has been reported to promote cell motility, invasion and metastasis. ${ }^{13}$ Cadherin genes may therefore also be involved in the response to anthracycline containing chemotherapy. In our study, however, we elected to concentrate on the expression of PRAME as it showed the highest expression in anthracycline containing chemotherapyresistant DLBCL patients. In these 45 patients, the PRAMEpositive patients $(\mathrm{n}=12)$ had a significantly worse clinical outcome than the PRAME-negative patients $(\mathrm{n}=33)(p=$ 0.0373, Fig. 2). PRAME thus has a definite influence on progression-free survival. And PRAME expression was thus a significant determinant of anthracycline containing chemotherapy outcome ( $p=0.032808$, Table 4$)$.

PRAME was first isolated as a human melanoma antigen by means of cDNA expression cloning using melanomareactive cytotoxic $\mathrm{T}$ cells $(\mathrm{CTL}){ }^{14}$ This gene encodes a 509amino acid protein of unknown function and is expressed in various cancers, including hematological malignancies. ${ }^{14}$ PRAME expression has previously been reported in a wide spectrum of hematopoietic diseases, including acute leukemia, ${ }^{15,16}$ myeloma ${ }^{17}$ and chronic myelocytic leukemia. ${ }^{18}$ In addition, PRAME expression seems to be stronger and more frequent in mantle cell lymphoma than in chronic lymphocytic leukemia. ${ }^{19}$ As the function of PRAME gene product(s) remains unknown, we cannot identify or even find a clue as to the mechanism by which PRAME expression influences the response to anthracycline containing chemotherapy. However, PRAME expression is an effective marker to determine response to anthracycline containing chemotherapy in 


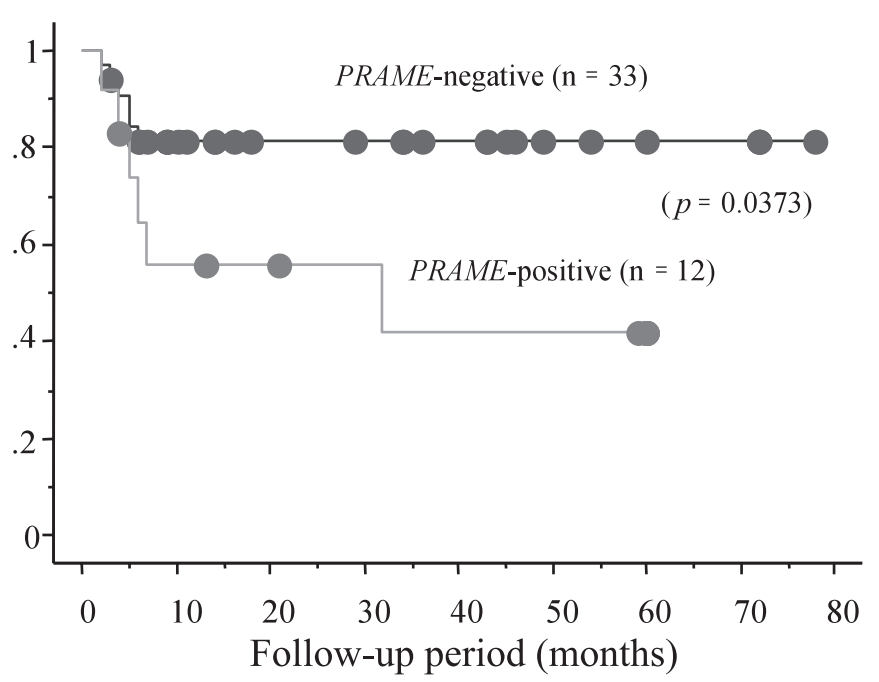

Fig. 2. Progression-free survival rates. Forty-five patients were selected for further analysis. The progression-free survival of preferentially expressed antigen of melanoma (PRAME)-positive patients $(n=12)$ was significantly worse than that of PRAMEnegative patients $(\mathrm{n}=33)(p=0.0373)$.

Table 4. Relationship between treatment response and PRAME expression

\begin{tabular}{ccc}
\hline Patients & $\begin{array}{c}\text { PRAME-positive } \\
\text { patients }(\mathrm{n}=12)\end{array}$ & $\begin{array}{c}\text { PRAME-negative patients } \\
(\mathrm{n}=33)\end{array}$ \\
\hline PD patients $(\mathrm{n}=12)$ & 6 & 6 \\
CR patients $(\mathrm{n}=33)$ & 6 & 27 \\
\hline
\end{tabular}

$\mathrm{PD}$ : progressive disease, $\mathrm{CR}$ : complete remission

Half of the PD patients were PRAME-positive, but only $18 \%$ of the CR patients were PRAME-positive. The effect of treatment was found to be related to PRAME expression.

DLBCLs. PRAME is also an antigen recognized by Tcells. ${ }^{14}$ The nonamer peptide LYVDSLFFL was identified as a T-cell epitope presented by HLA-A*2402 on the cell surface of melanoma cells, and was recognized by a CTL clone generated from a patient with melanoma. This CTL clone, which expresses the killer inhibitory receptor (KIR), could kill only target cells lacking HLA-Cw7. Matsushita et al. ${ }^{20}$ also demonstrated that this CTL clone could lyse HLA-A*2402positive and PRAME-positive leukemia cell lines and dissected leukemia cells in the presence of an anti-HLA-B, C antibody, which blocks interaction between KIR and HLAC. ${ }^{21}$ These results suggest that the PRAME protein is processed and presented on the cell surface of leukemia cells and is possibly a target antigen for CTL in patients with hematological malignancies. Matsushita et al. ${ }^{21}$ further screened PRAME expression in 98 Japanese patients and found that PRAME expression was high in $42 \%$ of the samples from patients with leukemia and lymphoma. All patients in our study underwent anthracycline containing chemotherapy. Recently, however, R-CHOP (Rituximab + CHOP) therapy has become the standard therapy for B-cell lymphoma. Rituximab induces apoptosis of lymphoma cells, thereby promoting phagocytosis and cross-priming of CTLs. ${ }^{22}$ It is therefore possible that CTLs could be activated in PRAMEpositive DLBCLs as a result of rituximab administration to enhance the tolerance to therapy and thereby its success rate.

In conclusion, in our study PRAME was identified as an "anthracycline containing chemotherapy response" marker for patients with DLBCL, particularly for malignancies without known genetic markers. PRAME expression correlated with resistance to first-time anthracycline containing chemotherapy. Based on the results of this study and those of others, we propose that PRAME may be a useful target antigen for immunotherapy of hematological malignancies. A possible clinical strategy may thus be to use PRAME-specific immunotherapy for anthracycline containing chemotherapy-resistant PRAME-positive DLBCLs. Further studies are needed, however, to investigate the exact relationship between PRAME expression and anthracycline containing chemotherapy.

\section{ACKNOWLEDGMENTS}

This study was supported in part by a Grant-in-Aid for Exploratory Research from the Ministry of Education, Culture, Sports, Science, and Technology of Japan.

\section{REFERENCES}

1 Coiffier B : Diffuse large cell lymphoma. Curr Opin Oncol 13 : 325-334, 2001

2 Villela L, López-Guillermo A, Montoto S, Rives S, Bosch F, Perales M, Ferrer A, Esteve J, Colomo L, Campo E, Montserrat E : Prognostic features and outcome in patients with diffuse large B-cell lymphoma who do not achieve a complete response to firstline regimens. Cancer 91: 1557-1562, 2001

3 Ohsawa M, Ikura Y, Fukushima H, Shirai N, Sugama Y, Suekane T, Hirayama M, Hino M, Ueda M : Immunohistochemical expression of multidrug resistance proteins as a predictor of poor response to chemotherapy and prognosis in patients with nodal diffuse large B-cell lymphoma. Oncology 68 : 422-431, 2005

4 Ohshima K, Kawasaki C, Muta H, Muta K, Deyev V, Haraoka S, Suzumiya J, Podack ER, Kikuchi M : CD10 and Bcl10 expression in diffuse large B-cell lymphoma : CD10 is a marker of improved prognosis. Histopathology 39 : 156-162, 2001

5 Adida C, Haioun C, Gaulard P, Lepage E, Morel P, Briere J, Dombret H, Reyes F, Diebold J, Gisselbrecht C, Salles G, Altieri DC, Molina TJ : Prognostic significance of survivin expression in diffuse large B-cell lymphomas. Blood 96 : 1921- 1925, 2000

6 Filipits M, Jaeger U, Pohl G, Stranzl T, Simonitsch I, Kaider A, Skrabs C, Pirker R: Cyclin D3 is a predictive and prognostic 
factor in diffuse large B-cell lymphoma. Clin Cancer Res 8 : 729-733, 2002

7 Alizadeh AA, Eisen MB, Davis RE, Ma C, Lossos IS, Rosenwald A, Boldrick JC, Sabet H, Tran T, Yu X, Powell JI, Yang L, Marti GE, Moore T, Hudson J Jr, Lu L, Lewis DB, Tibshirani R, Sherlock G, Chan WC, Greiner TC, Weisenburger DD, Armitage JO, Warnke R, Levy R, Wilson W, Grever MR, Byrd JC, Botstein D, Brown PO, Staudt LM : Distinct types of diffuse large B-cell lymphoma identified by gene expression profiling. Nature 403 : 503-511, 2000

8 Rosenwald A, Wright G, Chan WC, Connors JM, Campo E, Fisher RI, Gascoyne RD, Muller-Hermelink HK, Smeland EB, Giltnane JM, Hurt EM, Zhao H, Averett L, Yang L, Wilson WH, Jaffe ES, Simon R, Klausner RD, Powell J, Duffey PL, Longo DL, Greiner TC, Weisenburger DD, Sanger WG, Dave BJ, Lynch JC, Vose J, Armitage JO, Montserrat E, López-Guillermo A, Grogan TM, Miller TP, LeBlanc M, Ott G, Kvaloy S, Delabie J, Holte H, Krajci P, Stokke T, Staudt LM ; Lymphoma/Leukemia Molecular Profiling Project: The use of molecular profiling to predict survival after chemotherapy for diffuse large-B-cell lymphoma. $\mathrm{N}$ Engl J Med 346 : 1937-1947, 2002

9 Shipp MA, Ross KN, Tamayo P, Weng AP, Kutok JL, Aguiar RC, Gaasenbeek M, Angelo M, Reich M, Pinkus GS, Ray TS, Koval MA, Last KW, Norton A, Lister TA, Mesirov J, Neuberg DS, Lander ES, Aster JC, Golub TR: Diffuse large B-cell lymphoma outcome prediction by gene-expression profiling and supervised machine learning. Nat Med 8: 68-74, 2002

10 Ohshima K, Karube K, Hamasaki M, Suefuji H, Tutiya T, Yamaguchi T, Suzumiya J, Kikuchi M: Imbalances of chemokines, chemokine receptors and cytokines in Hodgkin lymphoma : classical Hodgkin lymphoma vs. Hodgkin-like ATLL. Int J Cancer 106: 706-712, 2003

11 Nishiu M, Yanagawa R, Nakatsuka S, Yao M, Tsunoda T, Nakamura Y, Aozasa K : Microarray analysis of gene-expression profiles in diffuse large B-cell lymphoma : identification of genes related to disease progression. Jpn J Cancer Res 93 : 894-901, 2002

12 Myers KA, Rahi-Saund V, Davison MD, Young JA, Cheater AJ, Stern PL: Isolation of a cDNA encoding 5T4 oncofetal trophoblast glycoprotein. An antigen associated with metastasis contains leucine-rich repeats. J Biol Chem 269 : 9319-9324, 1994

13 Hazan RB, Phillips GR, Qiao RF, Norton L, Aaronson SA :
Exogenous expression of $\mathrm{N}$-cadherin in breast cancer cells induces cell migration, invasion, and metastasis. J Cell Biol 148 : 779- 790,2000

14 Ikeda H, Lethé B, Lehmann F, van Baren N, Baurain JF, de Smet C, Chambost H, Vitale M, Moretta A, Boon T, Coulie PG: Characterization of an antigen that is recognized on a melanoma showing partial HLA loss by CTL expressing an NK inhibitory receptor. Immunity 6: 199-208, 1997

15 van Baren N, Chambost H, Ferrant A, Michaux L, Ikeda H, Millard I, Olive D, Boon T, Coulie PG : PRAME, a gene encoding an antigen recognized on a human melanoma by cytolytic $\mathrm{T}$ cells, is expressed in acute leukaemia cells. Br J Haematol 102 : 1376-1379, 1998

16 Greiner J, Ringhoffer M, Simikopinko O, Szmaragowska A, Huebsch S, Maurer U, Bergmann L, Schmitt M: Simultaneous expression of different immunogenic antigens in acute myeloid leukemia. Exp Hematol 28 : 1413-1422, 2000

17 van Baren N, Brasseur F, Godelaine D, Hames G, Ferrant A, Lehmann F, André M, Ravoet C, Doyen C, Spagnoli GC, Bakkus M, Thielemans K, Boon T: Genes encoding tumor-specific antigens are expressed in human myeloma cells. Blood 94 : 1156-1164, 1999

18 Watari K, Tojo A, Nagamura-Inoue T, Nagamura F, Takeshita A, Fukushima T, Motoji T, Tani K, Asano S : Identification of a melanoma antigen, $P R A M E$, as a BCR/ABL-inducible gene. FEBS Lett 466 : 367-371, 2000

19 Proto-Siqueira R, Falcào RP, de Souza CA, Ismael SJ, Zago MA : The expression of PRAME in chronic lymphoproliferative disorders. Leuk Res 27 : 393-396, 2003

20 Matsushita M, Yamazaki R, Ikeda H, Kawakami Y: Preferentially expressed antigen of melanoma (PRAME) in the development of diagnostic and therapeutic methods for hematological malignancies. Leuk Lymphoma 44 : 439-444, 2003

21 Matsushita M, Ikeda H, Kizaki M, Okamoto S, Ogasawara M, Ikeda Y, Kawakami Y: Quantitative monitoring of the PRAME gene for the detection of minimal residual disease in leukaemia. $\mathrm{Br}$ J Haematol 112: 916- 926, 2001

22 Selenko N, Maidic O, Draxier S, Berer A, Jäger U, Knapp W, Stöck1 J : CD20 antibody (C2B8)-induced apoptosis of lymphoma cells promotes phagocytosis by dendritic cells and cross-priming of $\mathrm{CD}^{+}$cytotoxic $\mathrm{T}$ cells. Leukemia $15: 1619-1626,2001$ 